\title{
1 Validation of an eDNA-based method for the detection of wildlife pathogens in
}

2 water

3 Natalie Sieber ${ }^{1,2, *}$, Hanna Hartikainen ${ }^{1,2,3}$, Christoph Vorburger ${ }^{1,2}$

$4{ }^{1}$ Eawag, Swiss Federal Institute of Aquatic Science and Technology, 8600

5 Dübendorf, Switzerland

$6 \quad 2$ ETH Zürich, Institute of Integrative Biology (IBZ), 8092 Zürich, Switzerland

$7{ }^{3}$ University of Nottingham, School of Life Sciences, University Park, NG7 2RD,

8 Nottingham, UK

9

*Email: Natalie.Sieber@eawag.ch

11

12 Running page head: Validation of eDNA pathogen detection method

This document is the accepted manuscript version of the following article:

Sieber, N., Hartikainen, H., \& Vorburger, C. (2020). Validation of an eDNA-based method for the detection of wildlife pathogens in water. Diseases of Aquatic organisms, 141, 171-184. https:// doi .org/10.3354/dao03524 


\section{Abstract}

Monitoring the occurrence and density of parasites and pathogens can identify high infection-risk areas and facilitates disease control and eradication measures.

Environmental DNA (eDNA) techniques are increasingly used for pathogen detection due to their relative ease of application. Since many factors affect the reliability and efficacy of eDNA-based detection, rigorous validation and assessment of method limitations is a crucial first step. We evaluated an eDNA detection method using insitu filtration of large volume water samples, developed to detect and quantify aquatic wildlife parasites by qPCR. We assessed method reliability using Batrachochytrium dendrobatidis, a pathogenic fungus of amphibians and the myxozoan

Tetracapsuloides bryosalmonae, causative agent of salmonid proliferative kidney disease, in a controlled experimental setup. Different amounts of parasite spores were added to tanks containing either clean tap water or water from a semi-natural mesocosm community. Overall detection rates were higher than $80 \%$, but detection was not consistent among replicate samples. Within tank variation in detection emphasises the need for increased site-level replication when dealing with parasites and pathogens. Estimated parasite DNA concentrations in water samples were highly variable and significant increase with higher spore concentrations was observed only for $B$. dendrobatidis. Despite evidence for PCR inhibition in DNA extractions from mesocosm water samples, the type of water did not affect detection rates significantly. Direct spiking controls revealed that the filtration step reduced detection sensitivity. Our study identifies sensitive quantification and sufficient replication as major remaining challenges of eDNA-based methods for detection of parasites in water. 
1 Key words: aquatic parasites, environmental DNA, Tetracapsuloides bryosalmonae,

2 Batrachochytrium dendrobatidis, in-situ filtration, quantitative real-time PCR 


\section{INTRODUCTION}

Monitoring the occurrence and prevalence of parasites and pathogens (hereafter summarised as parasites) is crucial for identification of high infection-risk areas, as shown for example in intestinal protozoan parasites (Helmi et al. 2011) and viruses (Grewar et al. 2019). Knowledge of pathogens in the environment is also important for human health and for the mitigation and prevention of zoonoses (Cunningham et al. 2017). Furthermore, it eases planning of disease control, and even informs eradication measures, for example of Schistosoma mansoni in Kenya (Sengupta et al. 2019). Therefore, comprehensive and regularly updated monitoring campaigns and surveillance for the creation of maps of parasite prevalence (Diarra et al. 2019) are important to implement management measures effectively. However, current management of most diseases is re-active, rather than pro-active, in that disease outbreaks are often detected by chance, then triggering measures and recommendations aimed at preventing further spread of the disease, such as Ebola in West Africa (Woolhouse et al. 2015). Conventional methods of parasite monitoring are cost- and labour-intensive, further impeding regular and comprehensive monitoring campaigns for parasites in the environment.

A fungus of the Phylum Chytridiomycota, Batrachochytrium dendrobatidis, causative agent of chytridiomycosis, has become infamous by causing mass mortalities in amphibians worldwide (Fisher et al. 2009). It is suspected to be a major driver of extinction of frog species (Skerratt et al. 2016) and has sparked extensive monitoring programs (Seimon et al. 2017). Conventional monitoring requires capture of sometimes rare and elusive amphibian species and taking skin swabs from the animals, before releasing them again. Fish hosts of Tetracapsuloides bryosalmonae (Myxozoa), causative agent of proliferative kidney disease (PKD) are less fortunate: 
1 after capture by electrofishing, pathological examination requires extraction of their

2 kidneys (Wahli et al. 2007). T. bryosalmonae causes high mortality in young-of-the-

3 year salmonid fish both in the wild and in fish farms in Europe and North America

4 (Clifton-Hadley et al. 1984, Hedrick et al. 1993). It is, therefore, of both conservational and economic import to closely monitor such diseases, whilst reducing the costs and conservation impacts of the surveillance itself.

As a non-invasive alternative to the described approaches, parasite detection in water samples using environmental DNA (eDNA) techniques (see Bass et al. 2015 for a review) could alleviate the aforementioned issues. Environmental DNA is defined as DNA that is not directly retrieved from the target organism, but from its environment and can be in the form of dead skin cells, mucus, blood, extracellular DNA and more (Thomsen \& Willerslev 2015). The same or similar eDNA techniques can be implemented for parasite detection, which, however, will mostly be detected as whole organisms, e.g. as zoospores or eggs. Research on detection in water has mostly focused on human parasites and pathogens, e.g. Listeria and Salmonella (Arvanitidou et al. 1997, Lyautey et al. 2007, Papić et al. 2019), Legionella (Moreno et al. 2019), and other potentially pathogenic microorganisms (Dalu et al. 2011). Furthermore, disease agents of economically important species such as Vibrio spp. in shellfish (Mok et al. 2019), or Myxobolus cerebralis, etiological agent of whirling disease in salmonids (Richey et al. 2018), are also of great interest. The advancement of molecular analytical methods has increased the potential of eDNA techniques and water sampling for parasite and pathogen detection across a broader range of systems and habitats and has been reviewed for microorganisms in drinking and recreational waters (Aw \& Rose 2012, Botes et al. 2013, Bonadonna et al. 2019) and eukaryote parasites (Bass et al. 2015). Crayfish plague agent Aphanomyces 
astaci spore concentrations, derived via quantitative real-time PCR (qPCR), positively correlated with parasite prevalence in captured signal crayfish from three Nordic lakes (Strand et al. 2014). Rusch et al. (2018) developed and successfully applied for the first time an eDNA-based detection method of Gyrodactylus salaris, an ectoparasite severely damaging Atlantic salmon populations and fisheries. These studies illustrate the value that molecular, or eDNA-based, detection techniques of parasites in water add to achieve deeper understanding of parasite distribution, abundance and spread, and ultimately, implementation of management measures.

However, as eDNA-based detection methods have moved out of their infancy, limitations have become more apparent. The target species might not be detected if it is rare or exists in low densities, such as invasive species at the invasion front (Jerde et al. 2011), or even in controlled experiments (Moyer et al. 2014). This could be the case for parasites, i.e. when infection prevalence and / or intensity in the host population is low or when, as for chronic infections, parasite shedding rate is low. This can be alleviated by collecting larger sample volumes, which in turn, however, could lead to increased accumulation of inhibitory compounds (Wintzingerode et al. 1997 and references therein). Coincidence of eDNA sampling timing with active parasite release from hosts can be crucial to maximise detection rates and therefore efficacy of the method. For parasites, this requires knowledge of periods of highest transmission and proliferation, which are often seasonal, e.g. related to water temperature (Mok et al. 2019), or can be tightly linked to host activities, such as the mating season in North American crayfish (Wittwer et al. 2018). Furthermore, most parasite DNA in environmental samples is in the form of spores, cysts or eggs, which need to be physically disrupted to access the DNA, requiring rigorous extraction protocols involving multiple rounds of alternate freezing and boiling of samples (Leles 
et al. 2009). These aspects all affect the reliability and efficacy of eDNA-based detection methods of parasites in water. Rigorous validation is therefore crucial to assess limitations of such methods.

In this study we validated an eDNA detection method developed for aquatic parasites. The method consists of in-situ filtration of large volume samples $(5 \mathrm{~L})$, a DNA extraction protocol deemed efficient at removing inhibition, and quantitative realtime PCR (qPCR) analysis, which is more sensitive than endpoint PCR (Wilcox et al. 2013). The study followed four main aims: Firstly, we aimed to assess reliability of the method, by investigating in a controlled environment the detection success of two parasite species: The amphibian chytrid fungus Batrachochytrium dendrobatidis, and the PKD-causing Tetracapsuloides bryosalmonae. This was achieved by adding different estimated concentrations of parasite spores to water tanks, followed by taking water samples from these tanks and measuring detection success in the water samples. The detection results were evaluated using occupancy models that estimated detection probabilities on tank, sample and qPCR replicate levels.

Occupancy models can quantify the reliability of the detection on different hierarchical levels, i.e. by quantifying the probability of detection in a single water sample, given a successful detection on the level of the sampling site from which multiple water samples were taken (Dorazio \& Erickson 2017). Occupancy models furthermore help in determining factors influencing detection success, such as elevation or water quality (Schmidt et al. 2013), or in our case, spore concentrations and water source. Secondly, to test the potential effect of inhibitors and to simulate more realistic conditions, half of the tanks were filled with water originating from a large mesocosm containing a semi-natural community of aquatic organisms, and compared to tanks filled with tap water. Thirdly, to estimate accuracy of the quantification with qPCR we 
compared estimated parasite DNA concentrations in water samples with spore concentrations in the tanks from where the samples were taken. Lastly, effects of the filtration process and the filter on detection variability were investigated by comparisons with samples directly spiked with spores in the lab, with and without filter. Validation of eDNA detection methods as conducted in this study are important for comparability between methods and help towards finding a consensus of which methods are most efficient and reliable for species detection in surveys.

\section{MATERIALS \& METHODS}

2.1. Generation of parasite spore solutions

Zoospores of Batrachochytrium dendrobatidis (isolate BEW2; Farrer et al. 2013) were obtained from cultures maintained according to Longcore et al. (1999) and Longcore et al. (2000; see the Supplement for a detailed protocol).To generate a solution containing $B$. dendrobatidis zoospores, culture medium was transferred to a $1.5 \mathrm{ml}$ plastic tube with a pipette, taking care not to touch the bottom of the culturing flask to prevent the collection of zoosporangia. Tetracapsuloides bryosalmonae spores were obtained from spore sacs extracted from bryozoans (Fredericella sultana) collected in the field one day prior to the experiment (River Glane, Switzerland, September 2018). Under a microscope with x8 magnification, T. bryosalmonae spore sacs were carefully excised from the zooids using forceps and collected in a separate petri dish. The spore sacs were ruptured with a needle to release the spores. The solution containing spores was pipetted into a $1.5 \mathrm{ml}$ plastic tube and mixed thoroughly by pipetting up and down.

For both parasites, ten $6.6 \mu$ subsamples of the solution were used to estimate spore densities microscopically using a counting chamber (KOVA Glasstic slide 10 with grids, Kova International Inc., Garden Grove, California). The mean spore 

2 further dilute the solutions to 200 spores per $\mathrm{ml}$, which were then stored in glass

concentration of both parasites was calculated from the ten subsamples and used to Schott flasks on ice until further usage on the same day. For dilution, clean tap water used for culturing bryozoans and fresh MGHTL culture media was utilised for $T$. bryosalmonae and B. dendrobatidis, respectively.

\subsection{Experimental setup}

The experiment with $B$. dendrobatidis was conducted on 14.11.2018 and the experiment with T. bryosalmonae on 18.09.2018 in a designated outdoor mesocosm facility on the roof of a laboratory building. The experiment included either 20 ( $B$. dendrobatidis) or 16 (T. bryosalmonae) $90 \mathrm{~L}$ polyethylene tanks (Eurokraft Kunststoffmulde by JOPA® Kunststofftechnik S\&W GmbH, Ahlen, Germany) filled with $20 \mathrm{~L}$ of either tap water or water obtained from a $1000 \mathrm{~L}$ mesocosm that simulated a natural pond community. The pond mesocosm was set up in May 2018. It contained tap water and local leaf litter as a source of nutrients, and it was inoculated with a townet sample of phyto- and zooplankton from nearby Lake Greifensee. In both experiments, the tanks holding $20 \mathrm{~L}$ of water were spiked with $100 \mu \mathrm{l}, 1 \mathrm{ml}$ or $10 \mathrm{ml}$ of spore solution for an estimated final concentration of 1,10 or 100 spores $\mathrm{L}^{-1}$ with four tanks per concentration. As a control, an additional four tanks, two for each water source, were not spiked, to test for background parasite DNA in the water sources $(n=16$ tanks in total). In the experiment with $B$. dendrobatidis, an additional treatment of 1000 spores $\mathrm{L}^{-1}$ in four tanks was included ( $n=20$ tanks in total), after the earlier experiment on T. bryosalmonae yielded surprisingly inconsistent detection at concentrations up to 100 spores $\mathrm{L}^{-1}$. All tanks were filled with source water (mesocosm or tap) before the start of the experiment, and three $5 \mathrm{~L}$ subsamples were collected and filtered from each tank immediately 
1 after addition of the parasite spore spike to the tank. Prior to filtering, the spike was

2 mixed into the tank water thoroughly by hand with clean gloves. The master spore

3 solution was kept on ice between filtration of different tanks. In order to accomplish each of the experiments in one day, spiking and filtration were conducted for both water types in two blocks, resulting in two replicates of each water quality treatment

6 ("mesocosm water" and "tap water") per spore concentration. Within blocks, the order 7 of filtration was randomised. Water was filtered from each tank as it would be in the field (Fig. 1), including a negative control at the beginning to test for cleanliness of the equipment. Sampling of one tank, including filtration of the negative control at the beginning, lasted around 45 minutes. The filters were stored on ice for a maximum of $4 \mathrm{~h}$ and frozen at $-80^{\circ} \mathrm{C}$ until DNA extraction.

\subsection{Sampling method}

Environmental DNA samples were collected using an in-situ filtration system with a peristaltic pump (Alexis peristaltic pump, Proactive Environmental Products LLC, Bradenton FL, USA). Figure 1 shows a sketch of the assembled filtration system. A PVC tube (length $=2 \mathrm{~m}, \varnothing$ (outer $/$ inner $)=13 / 10 \mathrm{~mm}$ ) is attached to a polypropylene plastic funnel (ø (outer / inner) $=100 / 95 \mathrm{~mm}$ ) with its opening covered with a synthetic polyamide mesh with particle retention size of $100 \mu \mathrm{m}$ (Sefar AG, Heiden, Switzerland), to serve as an inlet for the unfiltered water. To ensure submersion, a $1 \mathrm{~kg}$ coated lead diving weight was attached to the funnel with a 20 $\mathrm{cm}$ long rope and a longer piece of rope was fastened to the weight to facilitate retrieval from the water. The PVC tube was connected to a silicone tube $(75 \mathrm{~cm}$ long, $\varnothing($ outer $/$ inner $)=10 / 5 \mathrm{~mm}$ ) with a plastic reducer (PP ø 8-12/4-8 mm). A filter holder (Swinnex, 47 mm, Merck Millipore, Schaffhausen, Switzerland) was attached to the other end of the silicone tube using two connectors (double nipple PVC $1 / 4^{\prime \prime} x$ 
$1 \quad 1 / 4 "$ inner thread and screw-in connector GES 6 R1/4“, straight 6 mm / R1/4"). A 75

$2 \mathrm{~cm}$ long PVC tube (ø (outer / inner) = $10 / 6 \mathrm{~mm}$ ) was fastened to the outlet of the

3 filter holder to direct the filtered water to a measuring bucket (Fig. 1).

4 A "site kit" was assembled and sealed under clean conditions in the lab (see Fig. S1

5 in the Supplement for a picture of its components). It consisted of a plastic bag

6 containing an assembled filtering apparatus with a ready to use glass fibre filter with

$71 \mu \mathrm{m}$ pore size and $47 \mathrm{~mm}$ diameter (Grade GF/B, Whatman, VWR, Dietikon,

8 Switzerland) in the filter holder, a pair of plastic forceps, three glass fibre filters, four 5

9 ml tubes (PowerWater DNA bead tubes, Qiagen AG, Hombrechtikon, Switzerland) and a pair of nitrile lab gloves. A new "site kit" was used for each experimental water tank. Parts of the equipment were cleaned and reused for the experiments since they had been used in the field before. Reused parts were the filter holder and its two Orings, the silicone tube, all the connectors, the forceps, the funnel and the weight including the ropes. The cleaning procedure for all parts included a minimum of 10 min soak in $2.5 \%$ diluted technical bleach (Sodium hypochlorite $\left(14 \% \mathrm{Cl}_{2}\right.$,) VWR, Dietikon, Switzerland), followed by a 10 min soak in de-ionised water. De-ionisation was achieved with reverse osmosis. Equipment was rinsed in MilliQ water and airdried on a lab bench, covered with household paper. To control for the cleanliness of the filtration equipment, a negative control was run through the system prior to sampling each tank. The negative control consisted of $5 \mathrm{~L}$ of MilliQ water in a flexible plastic container (Brainypack, Bottleshop, Menshen Schweiz GmbH, Obernau, Switzerland).

Before sampling, wearing the gloves included in the site kit, the silicone tube was inserted into the pump head and the short PVC tube end was put into the bucket and secured in place with a clamp. The negative control was then filtered, with a helper pouring the water into the funnel held by the person with the gloves. After filtration 
1 the filter holder was opened, and the filter carefully folded with the feed side inwards

2 using forceps and put into a $5 \mathrm{ml}$ tube. A new filter was inserted into the holder and

3 the funnel was lowered into the experimental tank by the rope attached to the weight.

$4 \quad$ After $5 \mathrm{~L}$ had been filtered the filter was exchanged as before. This procedure was

5 repeated until three $5 \mathrm{~L}$ water samples were filtered, in addition to the negative

6 control. The tubes containing the samples were stored on ice for a maximum of four

7 hours and then put to $-80^{\circ} \mathrm{C}$ until extraction.

8

9

2.4. Validation of the T. bryosalmonae spike consistency

In a validation experiment, the spore solution of $T$. bryosalmonae was added to prewetted filter papers directly, omitting the filtration step. This experiment could not be conducted with $B$. dendrobatidis due to lack of remaining spore solution. The filters were spiked with the number of spores they would theoretically have captured in the experiment according to the spore concentrations in the tank, i.e. for $5 \mathrm{~L}$ from a 1 spore $\mathrm{L}^{-1}$ tank $=5$ spores and then 50 and 500 spores, respectively, for the 10 and 100 spores $\mathrm{L}^{-1}$ concentrations. Filters were placed onto petri dishes and the adequate amount of spore solution was pipetted onto the filter. Before spiking with spores, to simulate the wetness of a filter during and after the filtration process, Sigma water was added to the filter up to a total liquid (spore solution $+\mathrm{H}_{2} \mathrm{O}$ ) of $1.5 \mathrm{ml}$ per filter, which was absorbed completely by the filter. Three filters per concentration were tested. To test the effect of filter presence on detection and concentrations of spiked parasite, the same number of spores were added to the DNA extractions without a filter. Due to a dwindling stock of $T$. bryosalmonae spore solution only three samples per 5 and 50 spores were obtained without filter. 
$1 \quad$ All extraction work was conducted in a dedicated lab only used for processing

2 sensitive samples with low DNA content and for pre-PCR work. The filters were

3 extracted following the DNEasy PowerWater Kit protocol (Qiagen AG,

4 Hombrechtikon, Switzerland) with the following adjustments: after adding $1 \mathrm{ml}$ of

5 solution PW 1 and shredding of the filter into small pieces using a pipette tip, the

6 tubes were incubated at $65^{\circ} \mathrm{C}$ for 10 minutes in an oven (VWR Peqlab, Dietikon,

7 Switzerland). After vortexing for 5 minutes at full speed on a Vortex-Genie 2 (WWR,

8 Dietikon, Switzerland) with a $5 \mathrm{ml}$ tube adapter (QIAGEN AG, Hombrechtikon,

9 Switzerland) samples were subjected to an additional incubation period of 10 minutes at $65^{\circ} \mathrm{C}$. Samples were then centrifuged at $8000 \times \mathrm{g}$ with an Eppendorf $5427 \mathrm{R}$ centrifuge and rotor FA-45-12-17 for $5 \mathrm{ml}$ tubes (VWR, Dietikon, Switzerland). The extraction protocol used is described in detail in the Supplement (Supplementary data 2). A no-template extraction control containing only a clean filter paper was included in all extraction runs. The processed samples were stored at $-20^{\circ} \mathrm{C}$ until further analysis.

\subsection{Real-time quantitative qPCR}

2.6.1. Reaction setup \& thermal cycling The samples were analysed with real-time quantitative PCR (qPCR) on a LightCycler 480 (Roche, Basel, Switzerland) for both parasite species. A QIAgility pipetting robot (Qiagen AG, Hombrechtikon, Switzerland) was used for setting up the reactions.

Reactions were run in triplicate. Each GPCR run included a five-fold dilution series of eight standards of a Gblocks fragment (Integrated DNA Technologies, see

Supplementary data 3) with DNA concentrations ranging from 69'335 copies $\mu^{-1}$ to 0.9 copies $\mu \mathrm{l}^{-1}$ to generate a standard curve, and a negative PCR control. To detect and quantify $B$. dendrobatidis DNA in water samples we used the TaqMan assay 
1 developed by Boyle et al. (2004), which was applied to water samples before (Walker

2 et al. 2007), using specific forward primer ITS1-3 Chytr (5'-

CCTTGATATAATACAGTGTGCCATATGTC-3'), reverse primer 5.8S Chytr (5'-

4

AGCCAAGAGATCCGTTGTCAAA-3') and minor groove binding probe Chytr MGB2 (5'-6FAM CGAGTCGAACAAAAT MGBNFQ-3'). Reactions contained $5 \mu \mathrm{l}$ of LightCycler 480 Probes Master buffer (Roche, Basel, Switzerland), both primers at concentrations of $900 \mathrm{nM}$, the MGB probe at $200 \mathrm{nM}$ and $2.5 \mu \mathrm{l}$ of DNA template for a total volume of $10 \mu \mathrm{l}$ per reaction. To detect and quantify $T$. bryosalmonae DNA in water samples we used the TaqMan assay developed by Carraro et al. (2018), which has already been used to detect $T$. bryosalmonae in water samples, with forward primer Tb_COI_F1q (5'-GGTTGTTTAGTTTGGGCTCACC-3'), reverse primer Tb_COI_R1q (5'-TCCCTGTAGGGACAGCTATTG-3') and TaqMan probe Tb_probe_COI_1 (5'-6FAM CAAGATCTTATTTTATGGCTGCCAC BHQ-1 NFQ-3'). Ten microliter reactions for $T$. bryosalmonae contained $5 \mu$ l of LightCycler 480 Probes Master buffer (Roche, Basel, Switzerland), forward primer at concentration of $300 \mathrm{nM}$, reverse primer at $900 \mathrm{nM}$ and $250 \mathrm{nM}$ for the probe and $2.5 \mu$ l of template DNA. To control for inhibition in water samples, a synthetic template (Carraro et al. 2017) was used (5'-

GTATTCCTGGTTCTGTAGGTTGAGCGTAAAACGACGGCCAGTGAATTGTAATAC GACATGGTCATAGCTGTTTCCCGATACGGAAGTCCAGTCACAT -3'). This internal positive control (IPC) does not match any published sequence data. The IPC reaction setup was as follows: $5 \mu \mathrm{l}$ of LightCycler 480 Probes Master buffer, forward primer MIMf (5'- GTATTCCTGGTTCTGTAGGTTGAGC -3') at concentration of $50 \mathrm{nM}$, reverse primer MIMr (5'- ATGTGACTGGACTTCCGTATCG -3') at $900 \mathrm{nM}$, the IPC hydrolysis probe (5'- Cy3 CGACGGCCAGTGAATTGTAATACGA BHQ-1-3') at 250 $\mathrm{nM}, 2.5 \mu \mathrm{l}$ of water sample DNA and the IPC at a final concentration of $8.33 \mathrm{E}-19 \mathrm{~mol}$ 
$\mathrm{L}^{-1}$, or 5.01833 copies reaction ${ }^{-1}$. The IPC was run separately from the parasite assays in triplicate for each sample.

Thermal cycling for all assays started with an initial ten minutes at $95^{\circ} \mathrm{C}$ to activate the DNA polymerase and denature template DNA, followed by 50 cycles of 15 seconds at $95^{\circ} \mathrm{C}$ and one minute at $60^{\circ} \mathrm{C}$. A short cooling step of ten seconds at $40^{\circ} \mathrm{C}$ at the end of the cycling is suggested by the manufacturer of the machine and was implemented here.

\subsubsection{Standard curve}

A double-stranded Gblocks fragment (Integrated DNA Technologies) consisting of target sequences of all assays used in this study was used to create a five-fold dilution series with 15 dilutions from concentrations of $21.67^{\star} 10^{7}$ to 0.035 copies $\mu^{-1}$. The Gblocks sequence information is listed in the Supplement (Supplementary data 3). For each parasite assay a qPCR run was conducted with 30 replicates each from the fifth to eleventh dilution of the initial dilution series, and 40 replicates each of dilutions 12 to 15 (see Table S1 in the Supplement for detailed results). All replicates in each dilution were positive up to dilution 12 (100\% detection). In dilution $13,50 \%$ of the replicates were positive for both $T$. bryosalmonae and $B$. dendrobatidis assays. Therefore, the mean cycle value (Cq-value) of positive replicates of the dilution with $50 \%$ detection (dilution $13=2.22$ copies reaction $^{-1}$ ) was defined as limit of detection (LOD) for each parasite assay, respectively ( $T$. bryosalmonae $\mathrm{Cq}=35.646, B$. dendrobatidis $\mathrm{Cq}=37.706)$. We are aware that this limit is less stringent than the frequently used $95 \%$ detection (Bustin et al. 2009), but we deem it more appropriate when dealing with low content eDNA samples of potentially dangerous pathogens. For the sake of comparability, we applied the LOD calculator method developed by Klymus et al. (2019), which determines the LOD concentration at $95 \%$ detection, to 
1 the assays used in this study, resulting in LOD concentrations of 10.27 copies

2 reaction ${ }^{-1}$ for $B$. dendrobatidis and 9.64 copies reaction $^{-1}$ for $T$. bryosalmonae. The

3 limit of quantification (LOQ) was defined as the concentration of the last dilution of

4 the linear range of the standard curve, which was at 22.2 copies $\mu^{-1}$ for both parasite

5 assays. Parameters for the standard curve were $R^{2}=0.9995$, slope $=-3.467$ and

6 efficiency $=94.30 \%$ for $B$. dendrobatidis and $R^{2}=0.9999$, slope $=-3.410$ and

7 efficiency $=96.46 \%$ for $T$. bryosalmonae. The standard curves used to define the

8 LOD and LOQ are visualised in Fig. S2 in the Supplement for both parasites. We

9 included dilutions six $\left(69.33^{*} 10^{3}\right.$ copies $\left.\mu^{l^{-1}}\right)$ to $13\left(0.89\right.$ copies $\left.\mu^{l^{-1}}\right)$ on each run for absolute quantification of the DNA samples of the same run.

\subsection{Data analysis}

The qPCR raw data was first prepared using the LightCycler 480 Software version

1.5.1 (Roche, Basel, Switzerland). Cq-values were determined with the Absolute

Quantification - Second Derivative Maximum method and the high confidence algorithm (LightCycler Software version 1.5.1). A water sample was considered positive if the DNA concentration of the target parasite exceeded the LOD in at least one of the three replicate $\mathrm{qPCR}$ reactions. Detection of the target parasite in a water tank was considered successful if at least one sample from the tank was positive for parasite DNA. Non-detections were considered as "no answer" (N.A.) and excluded from calculations of the mean. Mean Cq-values or DNA concentrations of water samples were calculated with values from positive qPCR replicates and mean values of tanks from mean values of water samples. Statistics were conducted in $\mathrm{R}$ version 3.6.1. (R Core Team 2019). The R package "eDNAOccupancy" (Dorazio \& Erickson 2017) was used for running hierarchical occupancy models and model selection to test if spore concentrations, water source, order of sampling, block and inhibition had 
an effect on detection probability. All occupancy models were run with $11^{\prime} 000$ iterations of the MCMC algorithm. Model selection was conducted using the posterior Predictive Loss (PPLC, Gelfand \& Ghosh 1998) and Watanabe-Akaike Information criterions (WAIC, Watanabe 2010). If the addition of a covariate or factor did not improve model fit, it was considered not to influence parasite DNA detection. The equation $1-(1-\theta)^{n} \geq 0.95$ was used to determine the number of water samples (n) required for successful detection probability of $95 \%$, with $\theta$ being the probability of detection of parasite DNA in a water sample.

Linear mixed effects models were used to test the effect of spore concentrations, water source, order of sampling and block on estimated parasite DNA concentrations, including tank and sample ID as nested random factors. Block was considered a fixed factor because it contained only two levels. After testing for model fit using AIC, order of sampling and block effects were pooled into the residual term since they did not improve the model fit and were not significant for either $B$. dendrobatidis $(p=0.845$ and $p=0.316$, respectively) or T. bryosalmonae $(p=0.692$, $p=0.728$, respectively)

Detection success between pipette-spiked filter and experimental samples containing the same number of spores was compared using Fisher's exact test for count data. Comparisons of parasite DNA concentrations between pipette-spiked samples with and without filter, and between pipette-spiked filter samples and experimental samples were conducted with linear models with spiked number of spores as a covariate. Significance scores of all linear models were extracted with type III analysis of variance with Satterthwaite's method.

Inhibition of water samples was quantified by calculating Cq-value differences between water samples spiked with IPC DNA and control samples containing MiliQ water spiked with IPC DNA. The larger the Cq-value differences, the more inhibited 
1 the sample, with $\Delta$ Cq-values $\geq 3$ signifying substantial inhibition. We tested the effect

2 of water source on inhibition using a Wilcoxon Rank Sum test.

\subsection{Detection consistency}

6 Batrachochytrium dendrobatidis DNA was successfully detected in 14 out of 16 spore-spiked tanks (87.5\%) and Tetracapsuloides bryosalmonae DNA in 10 out of 12 tanks (83 \%). The two tanks where detection failed for B. dendrobatidis were spiked at concentrations of 1 and 100 spores $L^{-1}$, for T. bryosalmonae at 10 and 100 spores $\mathrm{L}^{-1}$. Detection of parasite DNA was not consistent among samples of the same tanks. DNA of $B$. dendrobatidis was successfully detected in all three samples of only two tanks, while five tanks had two, and the rest had one DNA-positive sample $(n=7)$. For T. bryosalmonae two tanks had two positive samples out of three, while the remaining eight had only one positive sample. The mean Cq-values and concentrations are reported in full in Table S2 in the Supplement. All negative controls filtering $5 \mathrm{~L}$ of MilliQ water to test the cleanliness of sampling equipment $(n=$ 36) and all samples from tanks without parasite spores $(n=24)$ were consistently negative.

Hierarchical occupancy models with constant parameters estimated occupancy probability in a tank to be $\Psi()=$.0.916 for $B$. dendrobatidis and $\Psi()=$.0.910 for $T$. bryosalmonae. The estimates of DNA detection per sample were $\theta()=$.0.53 and $\theta($. $=0.356$, respectively. Thus, to reach detection rates per tank of $95 \%$ or above, four and seven water samples per tank need to be taken for $B$. dendrobatidis and $T$.

24 bryosalmonae, respectively. Detection probability in a qPCR replicate, given successful parasite detection in the sample, was estimated to be $p()=$.0.665 and $p($. 
$1=0.955$, respectively. Batrachochytrium dendrobatidis model fit improved when spore

2 concentration and water source were added as covariates at the qPCR replicate

3 level. This result suggests that $B$. dendrobatidis DNA detection in positive samples at

4 the level of qPCR replicates was more likely in tap water samples ( $p$ (tap water) $=$

$5 \quad 0.813$ versus $p($ mesocosm water $)=0.553)$ and in tanks with higher spore

6 concentrations $\left(p\left(1\right.\right.$ spore $\left.L^{-1}\right)=0.576, p\left(10\right.$ spores $\left.L^{-1}\right)=0.579, p\left(100\right.$ spores $\left.L^{-1}\right)=$

$7 \quad 0.608, p\left(1000\right.$ spores $\left.\left.L^{-1}\right)=0.843\right)$. Since none of the covariates improved $T$.

8 bryosalmonae model fit, detection success did not depend on water source or spore

9 concentrations per tank. All tested models are listed in Table S3 in the Supplement.

\subsection{Real-time qPCR inhibition}

Most samples from the $B$. dendrobatidis experiment with water originating from the mesocosm (19 of 24) showed signs of inhibition according to IPC Cq-value shifts, while none of the tap water samples seemed to be affected ( $p<0.001$; Fig. 2$)$. In contrast, only three mesocosm water samples were affected by inhibition (Cq-value shift $>3$ cycles) in the $T$. bryosalmonae experiment (conducted at a different time point) and therefore, no significant effect of water source on inhibition was detected $(p=0.064)$.

3.3. Quantification of parasite eDNA

Parasite DNA concentrations in water samples increased significantly with higher spore concentrations in tanks for $B$. dendrobatidis $(F=4.787, p=0.041$; Fig. 3a), but not $T$. bryosalmonae $(F=1.239, p=0.29$; Fig. $3 b)$. Water source did not influence DNA concentration estimates of either parasite $(F=0.115, p=0.738$, and $F=0.09, p$ 
$1=0.771$, respectively). Parasite DNA concentrations on qPCR replicate level versus

2 tank spore concentrations are visualised in Fig. S3 in the Supplement.

3.4. Effect of filtration and extraction on Tetracapsuloides bryosalmonae detection and quantification

Tetracapsuloides bryosalmonae DNA was successfully detected in all replicates of samples where no filter paper was introduced. No significant differences in $T$. bryosalmonae DNA detection success between pipette-spiked filters and filters from experimental samples were observed $(p=0.119)$. No-filter samples of $T$. bryosalmonae yielded higher DNA concentration estimates than pipette-spiked filters $\left(F_{1,9}=52.281, p<0.001 ;\right.$ Fig. 4$)$ with significant differences in concentrations depending on the number of spores per sample $\left(F_{1,9}=53.785, p<0.001\right)$. The increase of $T$. bryosalmonae DNA concentration in samples with 50 spores compared to samples with five spores, was significantly different between no-filter and pipettespiked filter samples (interaction: $F_{1,9}=11.469, p=0.008$ ). Pipette-spiked filter samples did not have higher T. bryosalmonae DNA concentrations than experimental filter samples $\left(F_{1,21}=0.119, p=0.733 ;\right.$ Fig. 4). $T$. bryosalmonae DNA concentrations of pipette-spiked filter samples significantly increased with increasing spores filter ${ }^{-1}$ $\left(F_{1,8}=27.675, p<0.001 ;\right.$ Fig. 4). The mean Cq-values and concentrations recorded from no-filter and pipette-spiked filter samples are found in Table S4 in the Supplement.

\section{DISCUSSION}

4.1. Parasite detection and occupancy

The detection success of parasite spores in water using eDNA techniques was 
samples, developed for application in the field. We detected DNA of Batrachochytrium dendrobatidis in 14 out of 16 , and of T. bryosalmonae in 10 out of 12 tanks spiked with the target parasite spores. Therefore, the overall detection rate was similar for both tested parasites, i.e. $87.5 \%$ for Batrachochytrium dendrobatidis and $83 \%$ for Tetracapsuloides bryosalmonae. However, per sample detection was far from perfect even under these controlled conditions. Sample level non-detections were observed at all spore densities of both target organisms. $B$. dendrobatidis DNA was detected in all three samples from two tanks only $\left(2 \times 100\right.$ spores $\left.L^{-1}\right)$, while most tanks yielded only one positive sample out of three $(n=7) . T$. bryosalmonae DNA was never detected in all three samples in any of the experimental tanks. Nondetections were not restricted to low concentration treatments, nor to mesocosm water where PCR inhibition was predicted to be higher (Fig. 2).

Inconsistency of detection in water samples can arise when the amount of DNA captured in a sample is low, i.e. around the limit of detection (LOD). We deliberately adopted a relatively permissive LOD for reporting of positive detections, in line with recommendations for low-DNA samples (Hunter et al. 2017). Since we expect most of the parasite DNA in water to originate from intact spores and not from free extracellular DNA, encounter rate with parasite spores might not be high enough for successful detection unless they occur in sufficient densities. In our experiments, the density of spores could have been reduced through adhesion of spores to plastic or glass surfaces (tank sides, bottle lid, pipette tips etc.), which would render them unavailable for capture via water filtration. However, T. bryosalmonae DNA concentrations of experimental water samples were not lower than pipette-spiked filter samples (Fig. 4), indicating that loss by adhesion in the tanks and by the filtering equipment was negligible. We note that detection rate did not increase with higher 
spore densities in our experiments, and even the lowest spore concentrations led to successful detections. This suggests that detection success may be compounded by other factors than low DNA concentrations, for example due to heterogeneous distribution of parasite spores in water.

Heterogeneity in the T. bryosalmonae experiment could have arisen by the presence of spore / sac wall clusters or by spores sticking together. Presence of spore sac fragments was not observed during counting, but cannot be completely excluded. Clumping of spores in dissected material is possible, as T. bryosalmonae spores contain four polar capsules, each with a polar filament used for attachment to the fish host (McGurk et al. 2005, Morris \& Adams 2007) and we cannot exclude the possibility that the spores could have formed clusters post-release. Further, parasite sacs likely contained spores in different stages of maturity, whereas spores released in natural conditions from live bryozoan hosts are likely to be a more homogenous population of mature spores (the parasite sacs generally burst inside the host and only spores are ejected into the water column; Hartikainen \& Okamura 2015). To further evaluate experimentally the consistency of $T$. bryosalmonae detection, inoculation with naturally released spores would be an informative addition to the quantitative results obtained here. $B$. dendrobatidis zoospores are motile and less likely to form aggregations (Berger et al. 1998). However, most spores encyst in under $24 \mathrm{~h}$ after their release from the zoosporangium (Berger et al. 2005) and move only short distances during that time (Piotrowski et al. 2004). The spores spiked into the tanks were of different ages. Therefore, we cannot exclude heterogeneous distribution of $B$. dendrobatidis due to formation of immobile cysts. Finally, insufficient mixing of the water could be a possible reason for heterogeneous distribution of spores in the tanks, since we only mixed the water before filtering the first sample of 
each tank, and the filtration of three $5 \mathrm{~L}$ samples took about 30 minutes. This might be enough time for spores to settle or otherwise distribute unevenly in the tank, although there was no pattern in the results suggesting this (e.g. no higher probability of detection in the first samples taken from a tank).

Many previous studies using vertebrates, e.g. fish (Klymus et al. 2015) and amphibians (Pilliod et al. 2013), or macrophytes (Gantz et al. 2018) have reported $100 \%$ detection rates in mesocosm studies. Such promising results may arise because of the continuous and more disperse release of DNA via dead cells, mucus, etc. from these organisms. Previous studies with invertebrates and parasites in mesocosms have reported more variable detection success, in accordance with our findings (but see Sengupta et al. 2019 for $100 \%$ detection efficiency of Schistosoma mansoni). Mauvisseau et al. (2019) sampled water from mesocosms containing Freshwater Pearl Mussels (Margaritifera margaritifera) and were able to detect their DNA in all mesocosms with only one of two assays used, with evidence for inconsistent detection in biological and technical replicates. Tapeworm Echinococcus multilocularis DNA was detected in all $10 \mathrm{~L}$ water samples spiked with 100 or $1000 \mathrm{E}$. multilocularis eggs, respectively, but only in two-thirds of samples spiked with 10 eggs (Lass et al. 2019). Furthermore, while detection rate from $1 \mathrm{~L}$ lake water samples spiked with 10 or 1000 spores of agent of the crayfish plague, Aphanomyces astaci, reached almost a $100 \%$, single spores were detected in only $73 \%$ of the filter samples (Strand et al. 2011).

The inconsistency of detection at water sample level is reflected in the detection probabilities estimated with occupancy models, i.e. $\theta()=$.0.53 and $\theta()=$.0.356 , for $B$. dendrobatidis and T. bryosalmonae, respectively. However, detection consistency 
was higher on tank level, i.e. $\Psi()=$.0.916 for $B$. dendrobatidis and $\Psi()=$.0.910 for $T$. bryosalmonae, and qPCR replicate level, i.e. $\mathrm{p}()=$.0.665 for $B$. dendrobatidis and $p()=$.0.955 for $T$. bryosalmonae. The former being probabilities of detecting the parasite when it is present in a tank, and the latter being probabilities of a positive detection in a replicate of a sample, given that the sample is positive. These results suggest that the highest inconsistencies in detection success occur at the sample level. According to per sample detection probabilities, a theoretical cumulative detection rate of $95 \%$ or above can only be reached if four water samples per tank for B. dendrobatidis and seven samples per tank for T. bryosalmonae, are taken. This is despite our liberal approach of accepting a single qPCR replicate above LOD as successful detection, which we consider appropriate for low-quantity eDNA samples.

Taking replicate samples per site thus seems to be a requirement for reliable detection. However, increasing the number of samples leads to higher processing effort and costs, requiring careful consideration of cost and benefit when planning surveys for parasites in water.

\subsection{Inhibition in water samples}

We observed inhibition of the IPC amplification in water originating from the mesocosm during the $B$. dendrobatidis experiment, but not during the $T$. bryosalmonae experiment (Fig. 2). In both experiments, the water came from the same mesocosm, but the experiments were separated by two months. Natural variation in the mesocosm communities (e.g. different phytoplankton densities) may thus explain the different levels of inhibition in DNA extractions between the two experiments. Larger water volumes increase the number of spores captured in a sample, but the downside of increasing volume is that it will potentially lead to higher inhibition of the samples if more inhibitory compounds accumulate. This can 
decrease the efficacy of eDNA-based monitoring methods (Harper et al. 2019). In our study, water source, and therefore inhibition, did not influence detection success on tank level of either parasite in our tank experiment (Fig. 3). However, B. dendrobatidis mesocosm water samples did have lower detection consistency on the qPCR replicate level than tap water samples $(p($ mesocosm $)=0.553, p(\operatorname{tap})=0.813)$, indicating a potential inhibition effect. This was not the case for T. bryosalmonae samples, which might explain the higher overall qPCR replicate detection probability of $T$. bryosalmonae $(p()=0.955$.$) compared to B$. dendrobatidis $(p()=0.665$.$) . No$ direct effect of the magnitude of inhibition (measured shift in IPC Cq-value between a clean water and experimental DNA extract) on detection success was indicated by the statistical analysis. It could be that the low amount of IPC template added to qPCR reactions (5 copies reaction ${ }^{-1}$ ) renders the IPC inhibition control more sensitive to inhibition than the parasite detection assays.

\subsection{Accuracy of quantification}

Parasite DNA concentration estimates in water samples increased with spore concentrations in tanks (Fig. 3). This relationship was statistically significant for $B$. dendrobatidis (Fig. 3a) and a similar trend is visible for T. bryosalmonae (Fig. 3b), even though it is not statistically significant. The difference likely resulted from the fact that the $B$. dendrobatidis experiment included tank concentrations of 1000 spores $\mathrm{L}^{-1}$, while the maximum concentration in the $T$. bryosalmonae experiment was 100 spores $L^{-1}$. Even though one correlation was statistically significant, the large variance in the data, especially in samples from tanks with high parasite concentrations, urges caution in interpreting the results quantitatively. An accurate quantification of parasite DNA concentrations is not fulfilled by the method used in this study, according to the data. A qualitative comparison of parasite spore 
1 abundance might be possible between sites, if enough water samples are taken.

2 Correlations between species densities and eDNA quantities has been previously

3 found for amphibians (Thomsen et al. 2012, Pilliod et al. 2013), crayfish (Harper et al.

4 2018) and freshwater snails (Mauvisseau et al. 2019) in mesocosms. Infection prevalence has been shown to positively correlate or temporally coincide with DNA concentrations in water of amphibian (Huver et al. 2015), crayfish (Strand et al. 2014), fish (Hallett et al. 2012) and human parasites (Wade et al. 2010). However, a precise quantitative relationship of eDNA concentrations in water and parasite densities is yet to be described.

4.4. Influence of filtration methodology on detection success

All qPCR replicates of $T$. bryosalmonae spore samples extracted without a glass fibre filter detected parasite DNA and yielded higher DNA concentration estimates compared to the same number of spores extracted from filters (Fig. 4). $T$. bryosalmonae detection success of pipette-spiked filter samples did not differ from containing DNA than some other filter types, potentially decreasing yield of target parasite DNA. Glass fibre filters (GF/B) employed in this study allow a large volume of water to be filtered, which is potentially important for detection of relatively rare 
detection efficiency, but it seems unlikely that detection of one spore $\mathrm{L}^{-1}$ could be consistently achieved with smaller sample sizes. Thus, the choice of filter type and volume of water sampled presents a trade-off that is perhaps of more importance in parasite detection than for eDNA studies in general.

\subsection{Implications for parasite detection in the field}

The inconsistent detection we observed when applying the method in a very simplified environment is rather sobering and contains an important message for real surveys: patchiness in detection is likely to be inherent to any experimental setting where parasites are assayed in subsamples taken from rivers or lakes. Knowledge of B. dendrobatidis and T. bryosalmonae densities in natural systems, or parasite release dynamics from host individuals, is sparse and difficult to estimate outside the laboratory settings (Maguire et al. 2016, Fontes et al. 2017). The range of spore concentrations tested in this experiment likely encompasses at least some of the concentrations encountered in the field. However, the influence of spatial and temporal fluctuations on spore densities is difficult to capture. Natural aquatic systems are complex in their hydrology and structure and thus, heterogeneous distribution and density of parasite spores and DNA, even on small scales, are expected (Shogren et al. 2017). This will particularly be the case in systems with low host abundance or parasite prevalence in the host, or where the exact sampling location and timing of sampling determines occurrence of parasite spores in a water sample. In this context, the overall detection rates obtained in this experiment were still high (87.5\% and $83 \%$ for $B$. dendrobatidis and T. bryosalmonae, respectively), thanks to replicated sampling and technical replication within samples. Notably, low spore densities down to one spore $\mathrm{L}^{-1}$ could still be detected, while no false positives were found in our study. For assessment of disease risk, the distinction between 
1 viable and non-viable parasites is important and poses additional challenges for

2 interpretation and application of monitoring results in management.

\section{CONCLUSIONS}

This study presents a validation of an eDNA-based method to detect parasite DNA in water. An in-situ filtration method was applied to water spiked with known amounts of spores in a controlled environment. This validation identified limits and remaining challenges of such monitoring methods, which can therefore be addressed and improved. Specifically, it showed that despite the high sensitivity of qPCR assays, detection can be very inconsistent even at high spore concentrations, presumably due to non-homogeneous spore distributions and variation introduced at the different processing steps (i.e. filtration and DNA extraction from filters). Being aware of the limitations of the method helps interpret the results from field surveys more adequately and to quantify uncertainties. In the present case, it highlights the need for sufficient replication of samples from the same collection site to maximise detection success. While we did observe a positive correlation between estimated DNA concentrations and the manipulated spore concentrations, the large variance of the data compromises the reliability of quantitative comparisons. In general, we advocate further studies that evaluate the feasibility of quantifying parasite loads in water at accuracy that is relevant for risk assessments and early warning systems of disease outbreaks. Our $5 \mathrm{~L}$ filtration method was generally as efficient at detecting 1 spore $L^{-1}$ than 100 spores $L^{-1}$, suggesting high sensitivity, albeit the patchy occurrence of false negatives. Studies such as ours can help practitioners decide which detection method to use for monitoring campaigns. Therefore, the development of standardised validation practices for eDNA-based methods used in species detection is an important step still to be undertaken by researchers to 
1 facilitate their widespread implementation. As a step further, field-based evaluations

2 of detection success are recommended to obtain the most relevant guidance for

3 monitoring campaign designs.

4

ACKNOWLEDGEMENTS

We thank Trenton Garner, Lola Brookes and Celia Serrano of the Zoological Society of London, and Matthew Fisher and Claudia Wierzbicki of Imperial College London for providing $B$. dendrobatidis DNA extracts for testing the qPCR assay, $B$. dendrobatidis isolates and instructions for culturing. We further thank Raffael Stegmayer, Bettina Dubach, Nora Weissert, Tamara Schlegel and Thomas Müller for their assistance in conducting the experiments. The research was supported by a grant from Eawag and by funds from ETH Zürich and the University of Applied Sciences and Arts Northwestern Switzerland (FHNW).

\section{LITERATURE CITED}

Arvanitidou M, Papa A, Constantinidis TC, Danielides V, Katsouyannopoulos V (1997) The occurrence of Listeria spp. and Salmonella spp. in surface waters. Microbiol Res 152:395-397

Aw TG, Rose JB (2012) Detection of pathogens in water: From phylochips to qPCR to pyrosequencing. Curr Opin Biotechnol 23:422-430

Bass D, Stentiford GD, Littlewood DTJ, Hartikainen H (2015) Diverse Applications of Environmental DNA Methods in Parasitology. Trends Parasitol 31:499-513

Berger L, Hyatt AD, Speare R, Longcore JE (2005) Life cycle stages of the amphibian chytrid Batrachochytrium dendrobatidis. Dis Aquat Org 68:51-63 
Berger L, Speare R, Daszak P, Green DE, Cunningham AA, Goggin CL, Slocombe R, Ragan MA, Hyatt AD, McDonald KR, Hines HB, Lips KR, Marantelli G, Parkes H (1998) Chytridiomycosis causes amphibian mortality associated with population declines in the rain forests of Australia and Central America. Proc Natl Acad Sci USA 95:9031-9036

Bonadonna L, Briancesco R, La Rosa G (2019) Innovative analytical methods for monitoring microbiological and virological water quality. Microchem J 150:1-8

Botes M, De Kwaadsteniet M, Cloete TE (2013) Application of quantitative PCR for the detection of microorganisms in water. Anal Bioanal Chem 405:91-108

Boyle DG, Boyle DB, Olsen V, Morgan JAT, Hyatt AD (2004) Rapid quantitative detection of chytridiomycosis (Batrachochytrium dendrobatidis) in amphibian samples using real-time Taqman PCR assay. Dis Aquat Org 60:141-148

Bustin SA, Benes V, Garson JA, Hellemans J, Huggett J, Kubista M, Mueller R, Nolan T, Pfaffl MW, Shipley GL, Vandesompele J, Wittwer CT (2009) The MIQE guidelines: Minimum information for publication of quantitative real-time PCR experiments. Clin Chem 55:611-622

Carraro L, Bertuzzo E, Mari L, Fontes I, Hartikainen H, Strepparava N, SchmidtPosthaus H, Wahli T, Jokela J, Gatto M, Rinaldo A (2017) Integrated field, laboratory, and theoretical study of PKD spread in a Swiss prealpine river. Proc Natl Acad Sci USA 114:11992-11997

Carraro L, Hartikainen H, Jokela J, Bertuzzo E, Rinaldo A (2018) Estimating species distribution and abundance in river networks using environmental DNA. Proc Natl Acad Sci USA 115:11724-11729 
1 Clifton-Hadley RS, Bucke D, Richards RH (1984) Proliferative kidney disease of

2 salmonid fish: a review. J Fish Dis 7:363-377

3 Cunningham AA, Daszak P, Wood JLN, Cunningham AA (2017) One Health ,

Dalu T, Barson M, Nhiwatiwa T (2011) Impact of intestinal microorganisms and protozoan parasites on drinking water quality in Harare, Zimbabwe. J Water Sanit Hyg Dev 1:153-163

Deiner K, Lopez J, Bourne S, Holman L, Seymour M, Grey EK, Lacoursière A, Li Y, Renshaw MA, Pfrender ME, Rius M, Bernatchez L, Lodge DM (2018) Optimising the detection of marine taxonomic richness using environmental DNA metabarcoding: the effects of filter material, pore size and extraction method. Metabarcoding and Metagenomics 2:1-15

Diarra B, Diarra M, Diall O, Bass B, Sanogo Y, Coulibaly E, Sylla M, Zhao W, Paone M, Cecchi G (2019) A national atlas of tsetse and African animal trypanosomosis in Mali. Parasites and Vectors 12:1-10

Djurhuus A, Port J, Closek CJ, Yamahara KM, Romero-Maraccini O, Walz KR, Goldsmith DB, Michisaki R, Breitbart M, Boehm AB, Chavez FP (2017) Evaluation of filtration and DNA extraction methods for environmental DNA biodiversity assessments across multiple trophic levels. Front Mar Sci 4:314

Dorazio RM, Erickson RA (2017) Ednaoccupancy: An r package for multiscale occupancy modelling of environmental DNA data. Mol Ecol Resour 18:368-380 

extract environmental DNA for detection and quantification of fish. Mol Ecol Resour 16:56-68

Farrer RA, Henk DA, Garner TWJ, Balloux F, Woodhams DC, Fisher MC (2013) Chromosomal Copy Number Variation, Selection and Uneven Rates of Recombination Reveal Cryptic Genome Diversity Linked to Pathogenicity. PLoS Genet 9:e1003703

Fisher MC, Garner TWJ, Walker SF (2009) Global Emergence of Batrachochytrium dendrobatidis and Amphibian Chytridiomycosis in Space, Time, and Host. Annu Rev Microbiol 63:291-310

Fontes I, Hartikainen H, Holland JW, Secombes CJ, Okamura B (2017) Tetracapsuloides bryosalmonae abundance in river water. Dis Aquat Org $124: 145-157$

Gantz CA, Renshaw MA, Erickson D, Lodge DM, Egan SP (2018) Environmental DNA detection of aquatic invasive plants in lab mesocosm and natural field conditions. Biol Invasions 20:2535-2552

Gelfand AE, Ghosh SK (1998) Model choice: A minimum posterior predictive loss approach. Biometrika 85:1-11

Grewar JD, Sergeant ES, Weyer CT, van Helden LS, Parker BJ, Anthony T, Thompson PN (2019) Establishing post-outbreak freedom from African horse sickness virus in South Africa's surveillance zone. Transbound Emerg Dis 66:2288-2296

Hallett SL, Bartholomew JL (2006) Application of a real-time PCR assay to detect and quantify the myxozoan parasite Ceratomyxa shasta in river water samples. 
Hallett SL, Ray RA, Hurst CN, Holt RA, Buckles GR, Atkinson SD, Bartholomew JL (2012) Density of the Waterborne Parasite Ceratomyxa shasta and Its Biological Effects on Salmon. Appl Environ Microbiol 78:3724-3731

Harper KJ, Anucha NP, Turnbull JF, Bean CW, Leaver MJ (2018) Searching for a signal: Environmental DNA (eDNA) for the detection of invasive signal crayfish, Pacifastacus leniusculus (Dana, 1852). Manag Biol Invasions 9:137-148

Harper LR, Buxton AS, Rees HC, Bruce K, Brys R, Halfmaerten D, Read DS, Watson H V, Sayer CD, Jones EP, Priestley V, Ma E, Medupin C, Burgess K, Garce S, Benson G, Boonham N, Griffiths RA, Lawson L (2019) Prospects and challenges of environmental DNA ( eDNA) monitoring in freshwater ponds. Hydrobiologia 826:25-41

Hartikainen H, Okamura B (2015) Ecology and Evolution of Malacosporean-Bryozoan Interaction. In: Myxozoan Evolution, Ecology and Development. Okamura B, Gruhl A, Bartholomew JL (eds) p 201-216

Hedrick RP, MacConnell E, de Kinkelin P (1993) Proliferative kidney disease of salmonid fish. Annu Rev Fish Dis 3:277-290

Helmi K, Skraber S, Burnet JB, Leblanc L, Hoffmann L, Cauchie HM (2011) Two-year monitoring of Cryptosporidium parvum and Giardia lamblia occurrence in a recreational and drinking water reservoir using standard microscopic and molecular biology techniques. Environ Monit Assess 179:163-175

Hunter ME, Dorazio RM, Butterfield JSS, Meigs-Friend G, Nico LG, Ferrante JA (2017) Detection limits of quantitative and digital PCR assays and their influence 

in presence - absence surveys of environmental DNA. Mol Ecol Resour 17:221229

Huver JR, Koprivnikar J, Johnson PTJ, Whyard S (2015) Development and application of an eDNA method to detect and quantify a pathogenic parasite in aquatic ecosystems. Ecol Appl 25:991-1002

Jerde CL, Mahon AR, Chadderton WL, Lodge DM (2011) 'Sight-unseen' detection of rare aquatic species using environmental DNA. Conserv Lett 4:150-157

Klymus KE, Merkes CM, Allison MJ, Jackson CA, Goldberg CS, Helbing CC, Hunter ME, Lance RF, Mangan AM, Monroe EM, Piaggio AJ, Stokdyk JP, Wilson CC, Richter CA (2019) Reporting the limits of detection and quantification for environmental DNA assays. Environ DNA 00:1-12

Klymus KE, Richter CA, Chapman DC, Paukert C (2015) Quantification of eDNA shedding rates from invasive bighead carp Hypophthalmichthys nobilis and silver carp Hypophthalmichthys molitrix. Biol Conserv 183:77-84

Lass A, Szostakowska B, Kontogeorgos I, Korzeniewski K, Karamon J, Sulima M, Karanis P (2019) First detection of Echinococcus multilocularis in environmental water sources in endemic areas using capsule filtration and molecular detection methods. Water Res 160:466-474

Leles D, Araújo A, Vicente ACP, Iñiguez AM (2009) Molecular diagnosis of ascariasis from human feces and description of a new Ascaris sp. genotype in Brazil. Vet Parasitol 163:167-170

Longcore JE (2000) Culture technics for amphibian chytrids: Recognizing, isolating and culturing Batrachochytrium dendrobatidis from amphibians. In: Proceedings 
of Getting the Jump! On Amphibian Diseases Conference / Workshop. Cairns, Australia, p 52-54

Longcore JE, Pessier AP, Nichols DK (1999) Batrachochytrium dendrobatidis gen. et sp. nov., a chytrid pathogenic to amphibians. Mycologia 91:219-227

Lyautey E, Lapen DR, Wilkes G, McCleary K, Pagotto F, Tyler K, Hartmann A, Piveteau P, Rieu A, Robertson WJ, Medeiros DT, Edge TA, Gannon V, Topp E (2007) Distribution and characteristics of Listeria monocytogenes isolates from surface waters of the South Nation River watershed, Ontario, Canada. Appl Environ Microbiol 73:5401-5410

Maguire C, DiRenzo G V., Tunstall TS, Muletz CR, Zamudio KR, Lips KR (2016) Dead or alive? Viability of chytrid zoospores shed from live amphibian hosts. Dis Aquat Org 119:179-187

Mauvisseau Q, Burian A, Gibson C, Brys R, Ramsey A, Sweet M (2019) Influence of accuracy, repeatability and detection probability in the reliability of speciesspecific eDNA based approaches. Sci Rep 9:1-10

McGurk C, Morris DJ, Bron JE, Adams A (2005) The morphology of Tetracapsuloides bryosalmonae (Myxozoa: Malacosporea) spores released from Fredericella sultana (Bryozoa: Phylactolaemata). J Fish Dis 28:307-312

Mok JS, Ryu A, Kwon JY, Kim B, Park K (2019) Distribution of Vibrio species isolated from bivalves and bivalve culture environments along the Gyeongnam coast in Korea: Virulence and antimicrobial resistance of Vibrio parahaemolyticus isolates. Food Control 106:106697 
potentially pathogenic Legionella inside free-living amoebae from water sources. Environ Res 176:108521

Morris DJ, Adams A (2007) Sacculogenesis and sporogony of Tetracapsuloides bryosalmonae (Myxozoa: Malacosporea) within the bryozoan host Fredericella sultana (Bryozoa: Phylactolaemata). Parasitol Res 100:983-992

Moyer GR, Díaz-Ferguson E, Hill JE, Shea C (2014) Assessing environmental DNA detection in controlled lentic systems. PLoS One 9:e103767

Papić B, Golob M, Kušar D, Pate M, Zdovc I (2019) Source tracking on a dairy farm reveals a high occurrence of subclinical mastitis due to hypervirulent Listeria monocytogenes clonal complexes. J Appl Microbiol 127:1349-1361

Pilliod DS, Goldberg CS, Arkle RS, Waits LP (2013) Estimating occupancy and abundance of stream amphibians using environmental DNA from filtered water samples. Can J Fish Aquat Sci 70:1123-1130

Piotrowski JS, Annis SL, Longcore JE (2004) Physiology of Batrachochytrium dendrobatidis, a chytrid pathogen of amphibians. Mycologia 96:9-15

R Core Team (2019) R: A language and environment for statistical computing. R Foundation for Statistical Computing, Vienna, Austria. https://www.r-project.org/

Richey CA, Kenelty K V, Hopkins KVS, Stevens BN, Mart B, Barnum SM, Hallett SL, Atkinson SD, Bartholomew JL, Soto E (2018) Distribution and Prevalence of Myxobolus cerebralis in Post fire Areas of Plumas National Forest : Utility of Environmental DNA Sampling. J Aquat Anim Health 30:130-143

Rusch JC, Hansen H, Strand DA, Markussen T, Hytterød S, Vrålstad T (2018) Catching the fish with the worm: A case study on eDNA detection of the 
monogenean parasite Gyrodactylus salaris and two of its hosts, Atlantic salmon (Salmo salar) and rainbow trout (Oncorhynchus mykiss). Parasites and Vectors $11: 1-12$

Schmidt BR, Kéry M, Ursenbacher S, Hyman OJ, Collins JP (2013) Site occupancy models in the analysis of environmental DNA presence/absence surveys: A case study of an emerging amphibian pathogen. Methods Ecol Evol 4:646-653

Seimon TA, Seimon A, Yager K, Reider K, Delgado A, Sowell P, Tupayachi A, Konecky B, Mcaloose D, Halloy S (2017) Term monitoring of tropical alpine habitat change , Andean anurans, and chytrid fungus in the Cordillera Vilcanota , Peru : Results from a decade of study. Ecol Evol 7:1527-1540

Sengupta ME, Hellström M, Kariuki HC, Olsen A, Thomsen PF, Mejer H, Willerslev E, Mwanje MT, Madsen H, Kristensen TK, Stensgaard AS, Vennervald BJ (2019) Environmental DNA for improved detection and environmental surveillance of schistosomiasis. Proc Natl Acad Sci USA 116:8931-8940

Shogren AJ, Tank JL, Andruszkiewicz E, Olds B, Mahon AR, Jerde CL, Bolster D (2017) Controls on eDNA movement in streams: Transport, Retention, and Resuspension. Sci Rep 7:5065

Skerratt LF, Berger L, Clemann N, Hunter DA, Marantelli G, Newell DA, Philips A, McFadden M, Hines HB, Scheele BC, Brannelly LA, Speare R, Versteegen S, Cashins SD, West M (2016) Priorities for management of chytridiomycosis in Australia: saving frogs from extinction. Wildl Res 43:105-120

Spens J, Evans AR, Halfmaerten D, Knudsen SW, Sengupta ME, Mak SST, Sigsgaard EE, Hellström M (2017) Comparison of capture and storage methods for aqueous macrobial eDNA using an optimized extraction protocol: advantage 
Strand DA, Holst-Jensen A, Viljugrein H, Edvardsen B, Klaveness D, Jussila J, Vrålstad T (2011) Detection and quantification of the crayfish plague agent in natural waters: Direct monitoring approach for aquatic environments. Dis Aquat Org 95:9-17

Strand DA, Jussila J, Johnsen SI, Viljamaa-Dirks S, Edsman L, Wiik-Nielsen J, Viljugrein H, Engdahl F, Vrålstad T (2014) Detection of crayfish plague spores in large freshwater systems. J Appl Ecol 51:544-553

Thomsen PF, Kielgast J, Iversen LL, Møller PR, Rasmussen M, Willerslev E (2012) Detection of a Diverse Marine Fish Fauna Using Environmental DNA from Seawater Samples. PLoS One 7:e41732

Thomsen PF, Willerslev E (2015) Environmental DNA - An emerging tool in conservation for monitoring past and present biodiversity. Biol Conserv 183:4-18

Wade TJ, Sams E, Brenner KP, Haugland R, Chern E, Beach M, Wymer L, Rankin CC, Love D, Li Q, Noble R, Dufour AP (2010) Rapidly measured indicators of recreational water quality and swimming-associated illness at marine beaches: A prospective cohort study. Environ Heal A Glob Access Sci Source 9:1-14

Wahli T, Bernet D, Steiner PA, Schmidt-Posthaus H (2007) Geographic distribution of Tetracapsuloides bryosalmonae infected fish in Swiss rivers: An update. Aquat Sci 69:3-10

Walker SF, Salas MB, Jenkins D, Garner TWJ, Cunningham AA, Hyatt AD, Bosch J, Fisher MC (2007) Environmental detection of Batrachochytrium dendrobatidis in a temperate climate. Dis Aquat Org 77:105-112 
1 Watanabe S (2010) Asymptotic equivalence of Bayes cross validation and widely applicable information criterion in singular learning theory. J Mach Learn Res $11: 3571-3594$

4 Wilcox TM, McKelvey KS, Young MK, Jane SF, Lowe WH, Whiteley AR, Schwartz MK (2013) Robust Detection of Rare Species Using Environmental DNA: The Importance of Primer Specificity. PLoS One 8

7 Wintzingerode F V., Göbel UB, Stackebrandt E (1997) Determination of microbial diversity in environmental samples: Pitfalls of PCR-based rRNA analysis. FEMS Microbiol Rev 21:213-229

Wittwer C, Stoll S, Strand D, Vrålstad T, Nowak C, Thines M (2018) EDNA-based crayfish plague monitoring is superior to conventional trap-based assessments in year-round detection probability. Hydrobiologia 807:87-97

Woolhouse MEJ, Rambaut A, Kellam P (2015) Lessons from Ebola : Improving infectious disease surveillance to inform outbreak management. Sci Transl Med $7: 1-9$ 


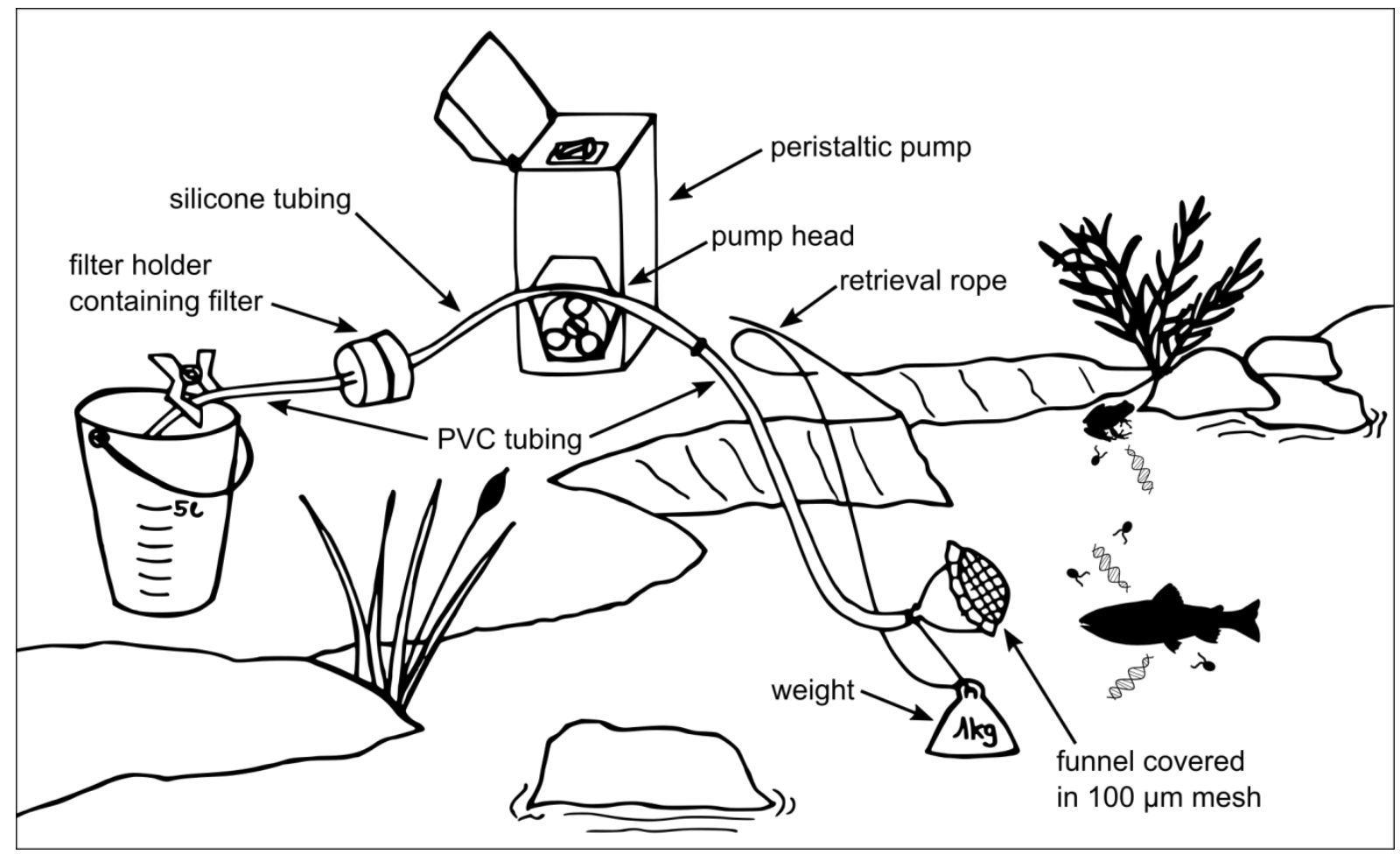

3 Fig.1: Sketch of the eDNA collection method developed in this study. A battery-

4 driven peristaltic pump is used to pump water through a submerged funnel covered in

5 a $100 \mu \mathrm{m}$ pore-sized mesh and filtered through a glass fibre filter contained within a

6 re-usable filter holder. Silicone tubing section compatible with the pump is extended

7 using disposable PVC tubing to minimise contamination and requirement for

8 cleaning. 


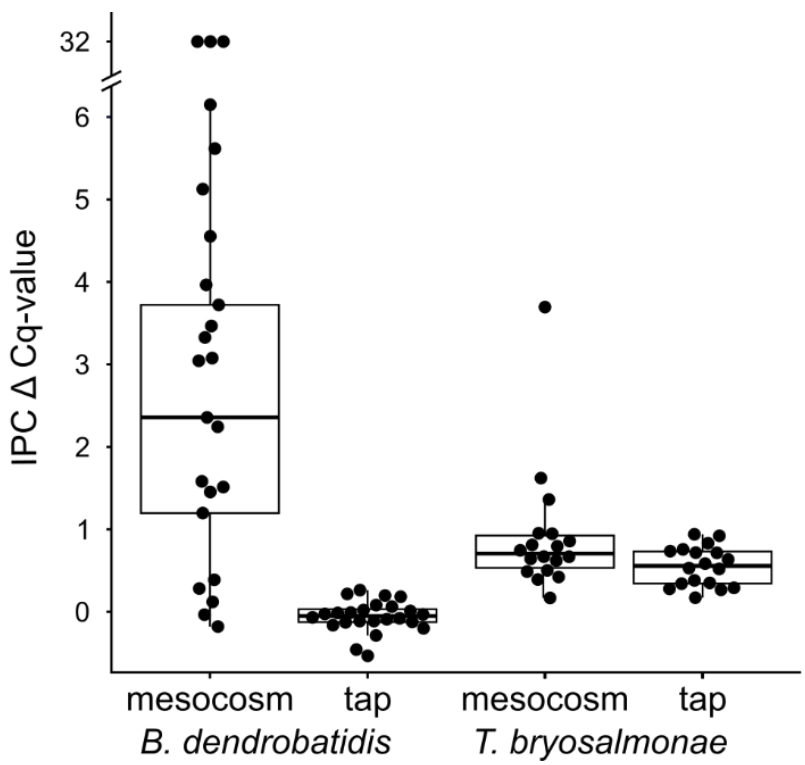

2 Fig. 2: Internal positive control qPCR cycle differences ( $\Delta$ Cq-values) between

3 mesocosm and tap water samples of the $B$. dendrobatidis and T. bryosalmonae

4 experiments. Points are jittered for better visibility. $\Delta$ Cq-values $\geq 3$ indicate presence

5 of inhibitors. The samples with $\Delta$ Cq-values $>30$ had no IPC DNA amplification and

6 therefore, $\Delta$ Cq-values were set to the Cq-value of the IPC control sample $(\mathrm{Cq}=$

7 32.22). 
a) B. dendrobatidis

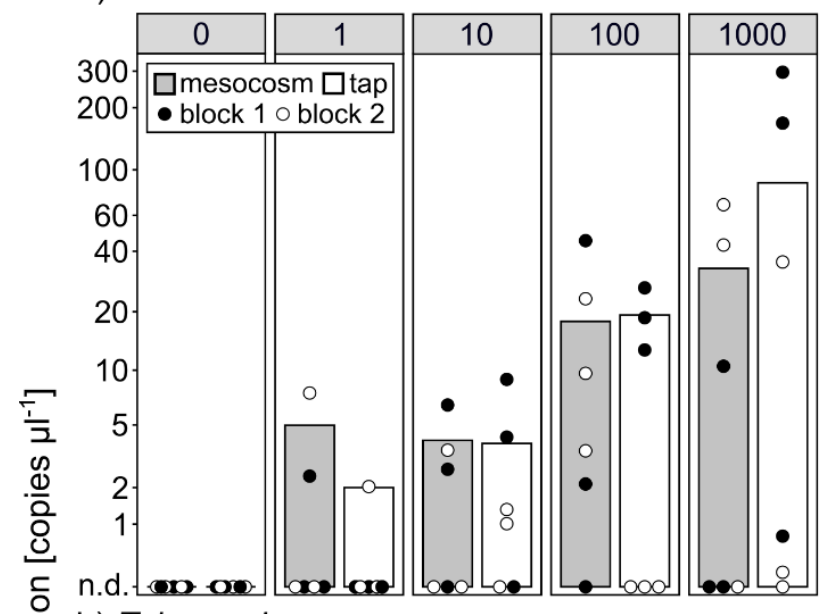

b) T. bryosalmonae

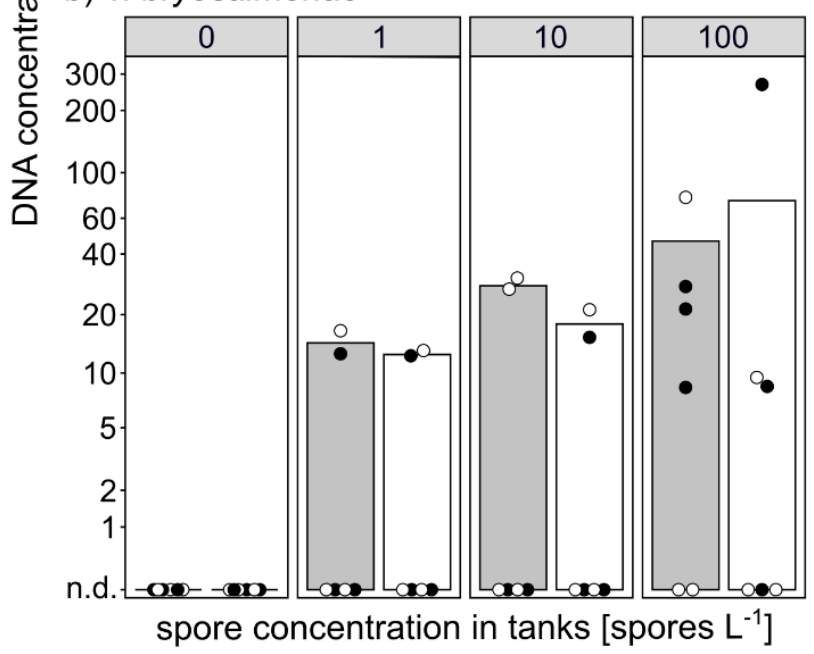

2 Fig. 3: Mean estimated parasite DNA concentrations in copies $\mu^{-1}$ per spore

3 concentration and water source (grey bars: mesocosm water, white bars: tap water) of a) Batrachochytrium dendrobatidis and b) Tetracapsuloides bryosalmonae. To account for the large variance, concentrations are presented on a logarithmic scale.

6 Successful detections only were used for calculating the means. The data points

7 show mean parasite DNA concentrations of qPCR replicates per $5 \mathrm{~L}$ water samples

$8 \quad(n=6$ per bar), with closed and open circles distinguishing samples from different

9 blocks (two tanks, one in each block, per water origin and spore concentration).

10 Points are jittered to visualise non-detections (n.d.). Parasite DNA concentrations on

11 qPCR replicate level versus tank spore concentrations are visualised in Fig. S3 in the

Supplement. 


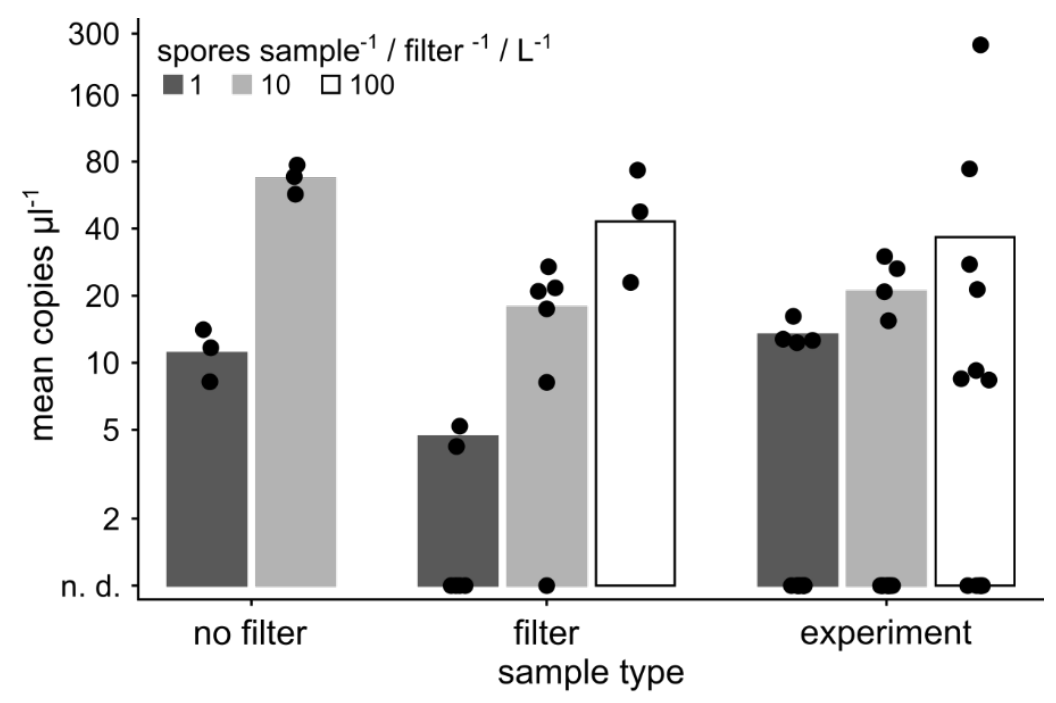

2 Fig. 4: Mean concentrations of T. bryosalmonae DNA in copies $\mu^{-1}$ of no filter

3 samples ( $n=3$ for each spores sample ${ }^{-1}$ treatment), pipette-spiked samples $(n=6$

4 each for treatments of five and 50 spores filter ${ }^{-1}$ and $n=3$ for the 500 spores filter ${ }^{-1}$

5 treatment) and water samples of the experiment ( $n=12$ for each spore concentration

6 [spores $\left.\left.L^{-1}\right]\right)$. Successful detections only were used for calculating the means. Points

7 show means of qPCR replicates for each sample and are jittered to visualise non-

8 detections (n.d.). The data that was used to create this figure is found in Table S5 in

9 the Supplement. T. bryosalmonae DNA concentrations on qPCR replicate level are

10 visualised in Fig. S4 in the Supplement. 